\title{
TELENOVELA: PRODUTO DE CONSUMO CULTURAL MASCULINO?
}

SOAP OPERA: A MALE CULTURAL PRODUCT

CONSUMPTION?

\begin{abstract}
CRISTIANe PoRTELA ${ }^{1}$
Doutoranda em Comunicação na Universidade Metodista de São Paulo (UMESP).

Mestre em Comunicação pela Universidade Federal de Pernambuco (UFPE).

Especialista em Docência do Ensino Superior pela Faculdade Santo Agostinho (FSA). Graduada em Comunicação Social - Habilitação Jornalismo - pela Universidade Federal do Piauí (UFPI). E-mail: crisportela14@yahoo.com.
\end{abstract}

\section{RESUMO}

Este artigo discute o consumo da telenovela, enquanto produto cultural, pelo gênero masculino. Para isto, parte do enfoque da formação identitária de homens e mulheres, observando alguns componentes culturais que interferem na constituição dessas identidades e como esses aspectos podem interferir no consumo da telenovela por homens de classes sociais com menor poder aquisitivo e que ainda possuem a televisão aberta como principal fonte de informação e entretenimento. Para a consecução da proposta realizou-se pesquisa de campo, com aplicação de questionário misto. Conclui-se, portanto, que, entre os dez entrevistados, apenas um não assiste telenovela e entre os que assistem todos se sentem atraídos pelo enredo.

Palavras-chave: Gênero. Identidade. Masculino. Telenovela.

\section{ABSTRACT}

The article discusses the soap opera consumption as a cultural product by men. Therefore, the cultural components with influence on the male and female identity are approached. It is observed how these aspects can act on the soap opera consumption by men from lower social class who have the non-subscribed TV as a main information and entertainment source. The field research was conducted by applying a questionnaire. It is concluded that among the 10 interviewees, only one did not have the habit of watching soap operas. All the other participants were attracted by the soap opera script.

Keywords: Gender. Identity. Male. Soap opera.

\section{Introdução}

$\mathrm{Na}$ sociedade contemporânea as questões culturais têm colaborado para a construção das identidades, definindo como a mulher e o homem assumem diferentes papéis sociais. Alguns aspectos, como a sexualidade e os relacionamentos afetivos, contribuem para definir posicionamentos tipicamente 
masculinos ou tipicamente femininos e servem como indicadores culturais marcantes na(s) postura(s) adotada(s) por cada gênero, ainda que não sejam definidores absolutos de tais posturas. No entanto, nem o homem nem a mulher já não procuram tão-somente adequar-se às diferenciações entre uma postura sexual marcadamente masculina e outra especificamente feminina, embora, mesmo de maneira sutil, até pouco tempo, essas posturas distintas fossem impostas culturalmente nas sociedades ocidentais.

Para o homem a virilidade estava assegurada pela variedade no número de parceiras, enquanto que à mulher era preciso resguardar-se até o casamento para não ser vista como leviana e imprudente. Tais diferenciações comportamentais já não mais existem e "a maior parte das pessoas, homens e mulheres, chega atualmente ao casamento trazendo com elas uma reserva substancial de experiência e conhecimento sexual" (GIDDENS, 1993, p. 21). Na vida matrimonial ao homem eram permitidos e aceitáveis relacionamentos extraconjugais enquanto às mulheres o adultério, além de inaceitável, era considerado abominável. Embora Giddens (1993) observe que o padrão duplo ainda exista, as mulheres já não são mais tolerantes a esse tipo de comportamento.

Ainda que não se possa definir os papéis sociais de homens e mulheres apenas considerando aspectos da sexualidade de cada um, ela certamente permite estabelecer a face definidora, mesmo que não definitiva, de tais identidades. Sob essa ótica, a da sexualidade, o homem ainda é visto pelo coletivo social, embora de forma inconsciente, como culturalmente superior, pois dele sempre foi esperada uma postura que mostre, sobretudo, força e virilidade. A sua identidade social é construída baseada nesse pressuposto, pois "o homem "verdadeiramente homem' é aquele que se sente obrigado a estar à altura da possibilidade que lhe é oferecida de fazer crescer sua honra buscando a glória e a distinção na esfera pública" (BOURDIEU, 2003, p. 64).

Todas essas exigências são impostas, quase sempre, pelos próprios homens a eles mesmos, e não para satisfazer e/ou impressionar as mulheres, mas como forma de competir com os outros homens e, também, para serem aceitos socialmente no grupo dos "verdadeiros homens". Assim sendo:

Certas formas de "coragem" [...] encontram seu princípio, paradoxalmente, no medo de perder a estima ou a consideração do grupo, de "quebrar a cara" diante dos "companheiros" e de ser remetido à categoria, tipicamente feminina, dos "fracos", dos "delicados", dos "mulherzinhas", dos "veados". (BOURDIEU, 2003, p. 66).

No âmbito do consumo cultural alguns produtos ainda são estigmatizados como fazendo parte da categoria tipicamente masculina e outros pertencentes à instância específica do feminino. Assistir jogos de futebol na televisão, por exemplo, enquadra-se no universo peculiar dos homens e o hábito de assistir telenovela é 
classificado como fazendo parte da natureza feminina.

Diante do exposto e considerando-se a relevância do tema, opta-se por investigar se a telenovela é produto de consumo cultural masculino, ou se ainda é vista pelos homens como forma de entretenimento próprio do gênero feminino. Para a consecução da pesquisa exploratória foram aplicados questionários a dez homens, selecionados aleatoriamente, de classes sociais com menor poder aquisitivo e que ainda possuem a televisão aberta como principal fonte de informação e entretenimento, considerando que "nem todas as classes assistem à televisão com a mesma intensidade [pois] há uma estreita relação entre a renda familiar e a audiência de TV" (MARCONDES FILHO, 1988, p. 82), ou seja, os indivíduos que possuem renda mais elevada possuem, consequentemente, outras opções de entretenimento.

No que diz respeito ao instrumento de coleta de dados, trata-se de questionário misto composto por sete questões, sendo quatro perguntas fechadas, duas abertas e uma mista. A primeira parte do questionário, intitulada Dados Pessoais, é composta apenas por uma pergunta fechada e investiga a faixa etária dos respondentes. No universo dos dez pesquisados prevalece a faixa etária acima de 35 anos, com cinco depoentes, seguida pela faixa etária de 26 a 30 anos, com quatro. Apenas um entrevistado possui idade entre 31 a 35 anos. Objetivando a consecução da proposta central desta pesquisa, a segunda parte do questionário engloba os seguintes pontos: a) freqüência de consu- mo; b) o que mais chama atenção em uma telenovela; c) motivação para o consumo; d) se a telenovela é "programa feminino".

\section{Feminino e Masculino: Identidades Distintas e/ou Complementares?}

Algumas características peculiarmente masculinas ainda permanecem bastante visíveis nas culturas contemporâneas do Ocidente, como a demonstração de força através da virilidade, mas a identidade masculina já não pode mais ser construída levando em consideração apenas tal parâmetro, como foi possível em um passado não muito distante.

Há culturalmente uma tendência prioritária de exigir do homem uma postura de "provedor e viril", como a dos "heróis" que povoam a literatura da cultura de massa, reforçada e cultivada pelo "imaginário coletivo" das sociedades contemporâneas, à medida que, "freqüentemente, a virtude do herói se humaniza, e seus poderes, ao invés de sobrenaturais, são a alta realização de um poder natural - a astúcia, a velocidade, a habilidade bélica, e mesmo a inteligência silogisticizante e o puro espírito de observação" (ECO, 2004, p. 246). Embora se saiba que tais poderes nunca aconteçam de forma plena, do homem é esperado que chegue o mais próximo possível de todas as formas que contribuam para idealizá-lo como dominador.

De outra perspectiva à mulher tem sido oferecido um papel que, mesmo de constante alteração, ainda the atribui características e atitudes "desvantajosas" 
em relação ao homem. Embora o movimento feminista tenha contribuído para impulsionar mudanças marcantes na posição social da mulher nos dias atuais, possibilitando reflexão mais acurada acerca de suas funções mais amplas, o passado histórico recente ainda mostra que "a masculinidade é identificada à ação, ao empreendimento, ao progresso, ou seja, ao campo dos negócios, da indústria, da ciência e da lei" (HUYSSEN, 1996, p. 42).

Não há, porém, uma universalidade marcante que possa ser utilizada como definidora do papel e da função social de cada gênero, pois de acordo com Zizek (1998) o homem e a mulher não são duas espécies de um gênero universal e neutro, visto que o entendimento de gênero como tal implica alguma dose de repressão ao feminino.

Assim, as próprias mutações sociais já não permitem que sejam delimitados comportamentos e/ou características culturalmente aceitos com distinção de gênero. Mesmo que historicamente haja uma marca definidora entre o feminino e o masculino, a própria gênese das mudanças tem conduzido a uma perda de força dessa separação, pois "a transitoriedade das coisas dificulta a preservação de todo sentido de continuidade histórica" (HARVEY, 2004, p. 22).

Ainda há, por certo, algumas posturas marcantes em termos de identidade que permanecem arraigadas em determinados posicionamentos femininos, como o fato de que "a maior parte das mulheres continua a identificar a sua inserção no mundo externo com o estabelecimento de liga- ções" (GIDDENS, 1993, p. 63). Isso se reflete na própria elaboração das falas, visto que "os homens em geral falam em termos de 'eu', enquanto as narrativas femininas sobre si mesmas tendem a ser expressadas em termos de "nós"' (ibid., p. 64).

Para o homem as alterações que contribuíram para essa (trans)formação de identidade, além de significativas, representaram uma substituição das práticas sociais já estabelecidas, mas "a maior mudança está, sem dúvida, no fato de que a dominação masculina não se impõe mais com a evidência de algo que é indiscutível" (BOURDIEU, 2003, p. 106). Os próprios homens também começam a desvendar posturas que eram inconcebíveis ao gênero masculino num passado recente, pois seriam entendidas como a negação da masculinidade e um verdadeiro acinte à sua posição de "macho".

Desse modo é expressivo afirmar que não existe uma identidade que diferencie de forma precisa os gêneros, pois um já não pode construir sua identidade separadamente do outro. A identidade feminina e a masculina nas culturas contemporâneas, além de não serem fixas e de se apresentarem em (trans)formação, possuem elementos que se completam.

As próprias questões envolvendo sexualidade e relacionamentos afetivos que em épocas passadas mostraram-se definidores culturais das identidades de homens e mulheres, e serviram como distintivos do que era uma identidade tipicamente masculina de outra especificamente feminina, nos dias atuais já não 
podem ser usadas como únicos parâmetros para tal distinção.

Hall (2004) coloca a identidade como "incompleta", "em processo" e por isso mesmo sempre "sendo formada", ainda que através de processos inconscientes. No caso dos gêneros ele cita que "as parte 'femininas' do eu masculino, por exemplo, que são negadas, permanecem com ele e encontram expressão inconsciente em muitas formas não reconhecidas, na vida adulta" (HALL, 2004, p. 38-39). Isso fornece exatamente a idéia de complementaridade estabelecida entre os gêneros, podendo servir para apagar de vez com a noção, ainda insistente em sobreviver, de que existe uma relação de dominação entre o feminino e o masculino.

Por isso, a identidade feminina não se (trans)forma sozinha e sem buscar elementos masculinos, assim como a identidade masculina necessita de elementos femininos para a sua (trans)formação. Essa forma de interação e complementaridade entre os gêneros é que pode possibilitar e fornecer um sentido completo de dinamicidade às sociedades contemporâneas. Considerando tal dinamismo, não se pode conceber, portanto, a distinção entre produtos culturais propriamente masculinos e outros típicos do gênero feminino.

\section{A Telenovela enquanto Produto de Consumo Cultural}

A telenovela brasileira é produto de consumo cultural com forte apelo junto ao público que ainda possui o veículo televisão como principal fonte de informação e entretenimento, pois ocupa lugar de destaque na grade de programação das principais emissoras de TV aberta do país. De acordo com Lima (2000), a constituição da telenovela no Brasil funciona

como espaço dialógico entre ficção e realidade, onde a construção do cotidiano representado incorpora os temas da realidade concreta para discuti-los, dar-lhes centralidade e colocá-los na ordem do dia das discussões da sociedade. Pauta para a mídia, alimentação para as conversas informais, propõe um debate de amplitude nacional, que ultrapassa as esferas convencionais e, de certo modo, restitui ao cidadão comum a possibilidade de opinar sobre questões de interesse da polis. (LIMA, 2000, p. 122).

Assim, a telenovela serve como entretenimento para qualquer indivíduo que esteja disposto a se inteirar e discutir questões cotidianas, independente se do gênero masculino ou feminino. Nesse sentido, temas como homossexualismo, alcoolismo, síndrome de Down, dentre outros, já fizeram, e continuam a fazer parte das discussões propostas pela telenovela. Os homens contemporâneos, e não apenas as mulheres, também precisam fazer parte dos debates suscitados, visto que principalmente a telenovela brasileira estabelece uma interação entre os cotidianos da ficção e da realidade (LIMA, 2000). Dessa forma, 
considerar a telenovela como um produto alienante porque conta uma história de amor, de muitos desencontros para um final feliz, sempre igual a si mesma, revela a desatenção para com sua face realista e dinâmica. É a sensibilidade para com temas geradores de conflitos de ordem social, de ordem pessoal ou ética, por exemplo, que garante a vitalidade da telenovela. Os temas se renovam levando em conta as variáveis que o próprio movimento sócio-históricopolítico coloca na dinâmica social. (LIMA, 2000, p. 123).

O gênero masculino, portanto, não deve estar à margem das interações provocadas pela telenovela e nem da dinamicidade dos temas propostos, pois, de acordo com Marcondes Filho (1988, p. 60) "a vida que a televisão mostra é então, para o homem e para a mulher, uma verdadeira troca, com vantagens, de sua vida real".

\section{O Consumo da Telenovela pelo Público Masculino}

As contribuições trazidas pela telenovela brasileira à sociedade transcendem as questões de consumo entre os gêneros masculino e feminino, bem como todas as críticas que possam ser feitas a esse produto cultural que domina o universo da televisão no nosso país. São temas sociais reais que invadiram, e continuam a invadir, os espaços da ficção televisiva, popularizando-se nas conversas do dia-a-dia e atingindo um público cada vez mais amplo.
Quem não se lembra da popularização de conhecimento sobre doações de órgãos, mães de aluguel, Internet, ou do serviço prestado por Explode Coração, de Glória Perez, ao incorporar uma campanha para localização de crianças desaparecidas, com efeitos que perduram na adesão de instituições e empresas que, até hoje, divulgam cartazes e relações de outras crianças? (LIMA, 2000, p. 123).

O gênero masculino não pode, dessa forma, excluir de seu cotidiano discussões tão amplas e que fazem parte da sua realidade social, tanto quanto da realidade feminina. Embora, na condição de "macho viril", possa temer ser julgado piegas, ao admitir interesse por um produto cultural, como a telenovela, que até pouco tempo era considerado tipicamente "diversão feminina". Essa postura, no entanto, já pode ser considerada ultrapassada, como comprova a atitude dos dez homens pesquisados nesse estudo, visto que nove deles admitiram que assistem telenovela. $\mathrm{O}$ único que não assiste afirma proceder assim por recomendação religiosa, mas não por considerar a telenovela "programa feminino". Segundo ele, sua religião acredita que as telenovelas trazem influência negativa para as pessoas, ou seja, alguns temas como espiritismo, adultério e alcoolismo são tratados de maneira diferente do que professa sua crença religiosa.

Dos nove entrevistados que assistem, quatro o fazem todos os dias e quatro vêem raramente, apenas um pesquisado assiste telenovela uma ou duas vezes por semana. Quando questionados 
sobre o que mais gostam de ver nas telenovelas, oito responderam que gostam dos atores, cinco que preferem os cenários e três que assistem para ver as roupas, principalmente nas telenovelas de época, sendo que cada entrevistado apontou mais de uma preferência ao mesmo tempo. Quando pesquisados sobre os motivos que os fazem ver telenovela as respostas foram as seguintes:

\begin{tabular}{|l|c|}
\hline MOTIVAÇÃO E/OU INTERESSE PELA TELENOVELA & $\mathbf{N}^{\circ}$ DE PESQUISADOS \\
\hline Interesse pelo enredo & 06 \\
\hline Falta de opção e/ou falta do que fazer & 02 \\
\hline Para ver a realidade que a telenovela reflete & 01 \\
\hline Por diversão & 01 \\
\hline Para passar o tempo & 01 \\
\hline Porque a TV está ligada & 01 \\
\hline TOTAL & $12^{*}$ \\
\hline
\end{tabular}

*Um mesmo entrevistado considerou mais de uma motivação e/ou interesse pela telenovela.

Tabela 01: Motivação e/ou interesse pela telenovela.

FONTE: a autora, 2009.

Quando questionados se consideram a telenovela "programa feminino", apenas três homens responderam que sim, enquanto a maioria, sete, respondeu que não. Dentre os que a consideram "diversão feminina", um alegou que "a telenovela aborda temas de interesse mais feminino, como moda, e também porque tem fofocas, coisas que as mulheres gostam". Outro afirmou que "a telenovela é 'programa de mulher' porque elas [as mulheres] têm mais tempo e disposição para assistir" e um entrevistado disse simplesmente que "os enredos são femininos". Embora todos os três tenham esse ponto de vista, eles fazem questão de afirmar que não possuem preconceitos e que os homens também podem assistir.

Dentre os sete que responderam que a telenovela não é "programa feminino", todos afirma- ram que essa separação já não é mais possível nos dias atuais: "Essa diferenciação entre 'programa de homem' e 'programa de mulher' já não existe nos dias de hoje, assim como não existe mais profissões masculinas e outras femininas", afirmou um dos entrevistados. "Muito homem já assiste telenovela e gosta", revelou outro. "Os homens já nem tem mais vergonha de admitir que vêem telenovelas", acrescentou mais um entrevistado.

\section{Considerações Finais}

Os resultados desse estudo demonstram, grosso modo, que a telenovela não é tão somente produto de consumo cultural especificamente feminino, mas que o gênero masculino também expressa interesse por esse tipo de entretenimento. $\mathrm{O}$ que comprova 
a afirmação de Arbex Jr. (2003, p. 48) de que "a telenovela adquiriu a densidade de um fato do mundo", ou seja, foi incorporada ao cotidiano dos brasileiros, e, na maioria dos casos, "as personagens [da telenovela] adquiriram visibilidade muito maior do que, em geral, aquela conquistada por políticos" (p. 48).

Dessa forma, dos dez homens que compõem a amostra dessa pesquisa, nove revelaram assistir telenovelas, e o único entrevistado que não assiste age dessa maneira por imposições de sua religião, pois considera que alguns temas polêmicos são tratados pela telenovela de maneira diferente do que professa sua crença religiosa. Todos os entrevistados que assistem fizeram questão de enfatizar que não nutrem preconceitos com relação à telenovela, nem a consideram um produto cultural inferior aos demais. De forma sucinta, seguem as principais inferências desse trabalho:

quatro dos entrevistados assistem telenovela todos os dias; a mesma quantidade assiste raramente e apenas um dos pesquisados assiste uma ou duas vezes por semana;

- para oito entrevistados, o que mais gostam nas telenovelas são os atores; cinco deles preferem os cenários e três gostam de ver as roupas, principalmente quando as novelas são de época;

- a maioria, ou seja, seis pesquisados, assiste telenovela com interesse no próprio enredo; dois assistem por falta de opção e/ou falta do que fazer. As outras respostas variam entre: um que gosta de ver a realidade que a telenovela reflete; um por diversão; um para passar o tempo e outro que assiste simplesmente porque a televisão está ligada;

- a maioria, sete entrevistados, também considera que a telenovela não é propriamente "programa feminino", pois entende que essa distinção já não é concebível nos dias atuais. Mesmo os três pesquisados que a consideram "diversão feminina" afirmam que não têm preconceitos com relação à telenovela.

\section{Referências}

ARBEX JR. José. Showrnalismo: a notícia como espetáculo. 3. ed. São Paulo: Casa Amarela, 2003.

BOURDIEU, P. A dominação masculina. 3. ed. Rio de Janeiro: Bertrand Brasil, 2003.

ECO, U. Apocalípticos e integrados. 6. ed. São Paulo: Perspectiva, 2004.

GIDDENS, A. A transformação da intimidade: sexualidade, amor e erotismo nas sociedades modernas. São Paulo: UNESP, 1993. 
HALL, S. A identidade cultural na pós-modernidade. 9.ed. Rio de Janeiro: DP \& A, 2004.

HARVEY, D. Condição pós-moderna: uma pesquisa sobre as origens da mudança cultural. 13. ed. São Paulo: Loyola, 2004.

HUYSSEN, A. A cultura de massa enquanto mulher: o "outro" do modernismo. In: . Memórias do modernismo. Rio de Janeiro: UFRJ, 1996. p. 41-69.

LIMA, Solange M. C. de. et al. A telenovela e o Brasil: relatos de uma experiência acadêmica. Revista Brasileira de Ciências da Comunicação, São Paulo, v. XXIII, n. 1, p. 118-136, jan./jun. 2000.

MARCONDES FILHO, C. Televisão: a vida pelo vídeo. São Paulo: Moderna, 1988.

ZIZEK, S. Multiculturalismo o la lógica cultural del capitalismo multinacional. In: JAMESON, F.; ZIZEK, S. Estudios culturales: reflexiones sobre el multiculturalismo. Buenos Aires/ Barcelona/ México: Paidós, 1998. p. 137-188. 